\title{
Long-Range Effect of Ion-Implanted Materials in Tribological Investigations
}

\author{
P. Budzyński ${ }^{a *}$, M. KAMiński ${ }^{a}$, K. PYSZniaK $^{b}$ AND M. Wiertel ${ }^{b}$ \\ ${ }^{a}$ Faculty of Mechanical Engineering, Lublin University of Technology, \\ Nadbystrzycka 36, 20-618 Lublin, Poland \\ ${ }^{b}$ Institute of Physics, M. Curie-Sklodowska University, \\ Plac Marii Curie-Sklodowskiej 1, 20-031 Lublin, Poland
}

\begin{abstract}
Microhardness results and the occurrence of radiation defects at a greater depth than the predicted implanted ion range indicate the presence of the so-called long-range effect. An attempt is made to determine the thickness of a layer with modified tribological properties by measuring friction and wear factors. Tribological tests are performed on the pin-on-disc stand. The real thickness of a layer with implantation-modified tribological properties can be determined via tribological testing by measuring the wear trace depth when the friction factor and/or wear of the implanted sample is close to that characteristic of an unimplanted sample. The predicted range of the implanted ions is estimated by the SRIM and SATVAL programs. The presence of the long-range effect is confirmed for the steel grades AISI 316L, H11, Raex 400, Hardox 450 as well as for the Stellite 6 and Ti6Al4V alloys. The modified layer thickness determined by tribological testing is considerably greater $(4.7 \div 16.7$ times $)$ than the initial range of the implanted nitrogen ions. The observed depth of changes in the tribological properties of the surface layer (due to the long-range effect) is consistent with the nanohardness results obtained for the steel grades AISI 316 and H11. An analysis of the content of elements on the sample surface as well as in its wear trace and wear products is performed by X-ray spectroscopy (EDS and WDXS). The results demonstrate that one of the causes of the long-range effect is the diffusion of nitrogen and carbon atoms in the friction zone during the tribological test.
\end{abstract}

DOI: 10.12693/APhysPolA.136.290

PACS/topics: 68.55.Ln, 62.20.Qp, 61.82.Bg, 61.80.--x

\section{Introduction}

Ion implantation changes physical, chemical, mechanical, and tribological properties of a metal surface layer. It is assumed that changes in the physical and chemical properties extend to a depth that is comparable to the range of implanted ions. These changes result from the effect of implanted ions and defects produced during implantation. However, the surface layer microhardness results demonstrate that the thickness of a layer with the increased microhardness can be greater, even to a large extent, than the range of the implanted ions. This phenomenon is known as the long-range effect [1]. Until recently this effect could only be confirmed by microhardness measurements. Although this effect was reported by Sharkeev et al. [2-4], its presence was undermined due to the difficulty with determining implantationmodified layer thickness via microhardness testing. This is due to the fact that an indenter of specific geometry (e.g. pyramid-shaped), having produced an indentation in a high-strength modified layer, is side-supported by this layer. As a result, the obtained thickness contains an error. It is assumed that the depth of indentation should not exceed 1/10 thickness of the layer being measured [5]. Despite this assumption, the authors of

*corresponding author; e-mail: p.budzynski@pollub.pl the above-mentioned papers [2,3] used the Vickers indenter in the shape of a square-based pyramid. They made an indentation of $1 \div 5 \mu \mathrm{m}$ under the load set equal to $15 \div 20 \mathrm{~g}$, in this way exceeding the implanted layer thickness several times. The authors of the present study attempt to determine the thickness of an implanted layer with modified tribological properties by measuring the friction factor and wear. This effect is explained in an interesting way. Sharkeev assumed that the longrange effect is caused by two factors: one, the shift of implantation-produced radiation defects to the inside of the sample, and, two, the defects which occur while the indenter is being driven into the sample [4]. In the light of the above, it seems necessary to investigate whether the afore-mentioned factors are the only cause of the long-range effect.

\section{Experimental details and discussion}

The friction factor and wear were measured under technically dry friction conditions. The tribological test was performed on a pin-on-disc stand with a Nano Tribometer (NTR2) manufactured by Anton Paar as well as on a test stand designed by one of the authors of this study [6]. The real thickness of the layer with tribological properties modified by ion implantation can be determined via tribological testing, by measuring the wear trace depth when the friction factor of the implanted sample is close to the value that is typical of unimplanted samples. 


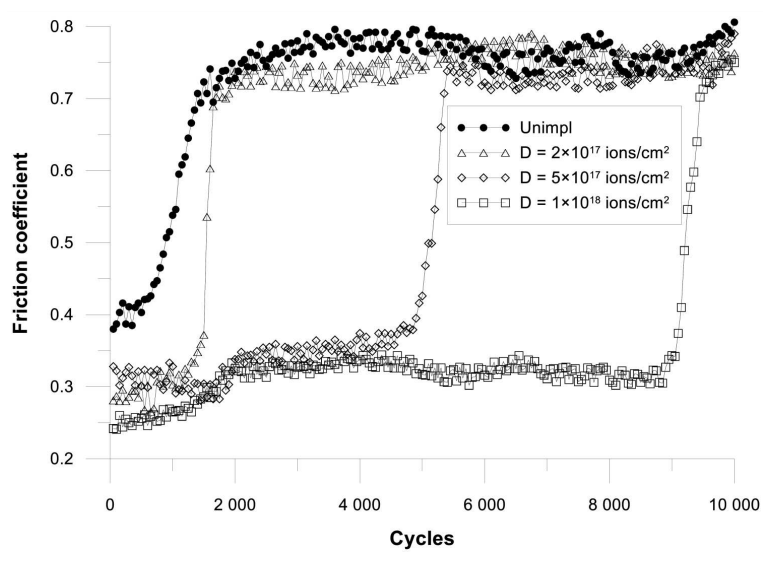

Fig. 1. Variations in the friction coefficient of Ti6Al4V samples implanted with nitrogen ions with an energy of $120 \mathrm{keV}$.

Variations in the friction factor occurring after the wear of the modified layer are clearly visible in the Ti6Al4V alloy sample (Fig. 1).

Following the nitrogen implantation, the friction factor of Ti6Al4V alloy decreases. The wear trace depth, which describes the moment when the friction factor of the implanted samples is equal to the friction factor of the unimplanted sample, can be used to determine thickness of the modified layer. The depth of the wear traces after tribological testing was determined based on their profilograms. Fig. 2 shows the profilograms of the wear traces obtained for the Ti6Al4V alloy sample. After 9550 measurement cycles, the friction factor of the implanted sample with a fluence of $1 \times 10^{18} \mathrm{~N}^{+} / \mathrm{cm}^{2}$ is equal to the friction factor of the unimplanted sample. This result indicates the wear of the modified layer. The wear trace depth is 3.0(1) $\mu \mathrm{m}$. The long-rage effect in the Ti6Al4V alloy sample implanted with nitrogen ions with an energy of $120 \mathrm{keV}$ and a fluence of $5 \times 10^{17} \mathrm{~N}^{+} / \mathrm{cm}^{2}$ extends to a depth of $2.9(1) \mu \mathrm{m}$. This method was first employed to investigate two steel grades: AISI 316L [7] and AISI H11 [8].

The presence of the long-range effect in tribological testing was confirmed for a series of metals and alloys. Table I lists the parameters describing the long-range effect in the tested materials. The predicted range of the implanted ions $R_{\mathrm{SRIM}}[\mu \mathrm{m}]$ was determined with the use of the SRIM program [9]. The thickness of the modified layer $R_{\mu}[\mu \mathrm{m}]$ determined by tribological test is much greater - it is $4.7 \div 16.7$ times greater than the initial range of the implanted nitrogen ions. The thickness of the modified layer determined by tribological testing is consistent with that obtained in the nanohardness tests for steels AISI 316 [7] and H11 [8]. The results demonstrate that the modified layer thickness increases with increase in the fluence of implanted nitrogen ions.

The next step was to find the causes of the decreased friction factor and wear, as well as to explain why the microhardness increased at the depth that is even several times greater than the initial range of the implanted ions. An analysis of the elements contents on the sample surface as well as in its wear trace and wear products was performed by energy dispersive X-ray spectroscopy (EDS).

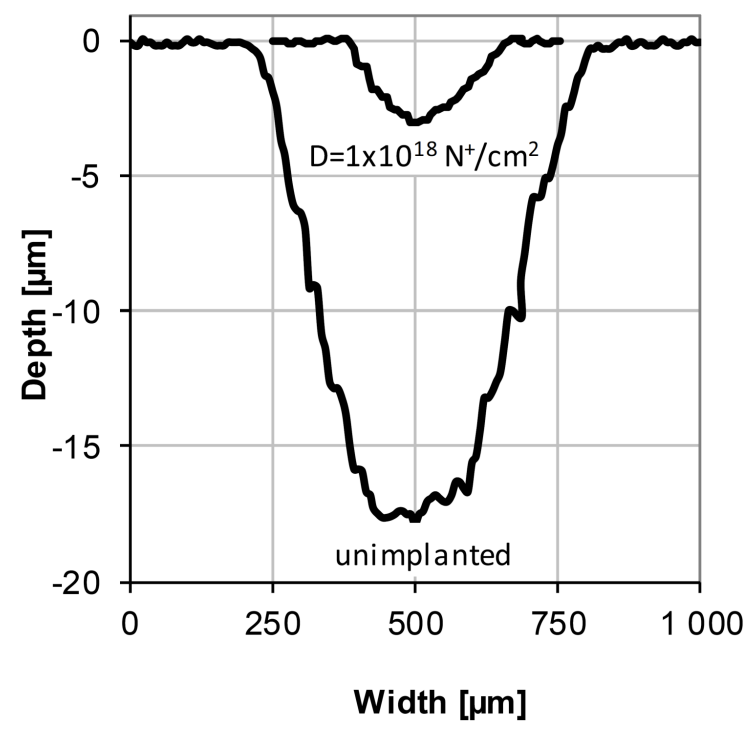

Fig. 2. Profilograms of the wear trace of the Ti6Al4V 6 alloy sample implanted with nitrogen ions with an energy of $120 \mathrm{keV}$ and a fluence of $1 \times 10^{18} \mathrm{~N}^{+} / \mathrm{cm}^{2}$ after 9550 cycles.

Parameters describing the long-range effect of nitrogen atoms in the materials under study.

TABLE I

\begin{tabular}{|c|c|c|c|c|c|c|}
\hline Sample, $E_{\text {impl }}[\mathrm{keV}]$ & Fluence [ions $/ \mathrm{cm}^{2}$ ] & $R_{S R I M}[\mu \mathrm{m}]$ & $R_{\mu}[\mu \mathrm{m}]$ & $R_{\mathrm{HV}}[\mu \mathrm{m}]$ & $k=R_{\mu} / R_{\mathrm{SRIM}}$ & Ref. \\
\hline Ti6Al4V, $120 \mathrm{keV}$ & $\begin{array}{l}2 \times 10^{17} \mathrm{~N}^{+} \\
5 \times 10^{17} \mathrm{~N}^{+} \\
1 \times 10^{18} \mathrm{~N}^{+}\end{array}$ & 0.42 & $\begin{array}{l}2.1(1) \\
2.9(1) \\
3.0(1)\end{array}$ & & $\begin{array}{l}5.0 \\
6.9 \\
7.1\end{array}$ & this study \\
\hline AISI H11, $120 \mathrm{keV}$ & $1 \times 10^{17} \mathrm{~N}^{+}$ & 0.24 & $4.0(1)$ & $4.2(2)$ & 16.7 & [8] \\
\hline Raex $400,65 \mathrm{keV}$ & $1 \times 10^{17} \mathrm{~N}^{+}$ & 0.17 & $2.3(1)$ & & 13.5 & [10] \\
\hline Hardox $450,65 \mathrm{keV}$ & $1 \times 10^{17} \mathrm{~N}^{+}$ & 0.17 & $2.1(1)$ & & 12.4 & [10] \\
\hline Stellite, $65 \mathrm{keV}$ & $\begin{array}{l}1 \times 10^{16} \mathrm{~N}^{+} \\
5 \times 10^{16} \mathrm{~N}^{+} \\
1 \times 10^{17} \mathrm{~N}^{+}\end{array}$ & 0.16 & $\begin{array}{l}1.0(1) \\
1.3(1) \\
2.0(1)\end{array}$ & & $\begin{array}{c}6.3 \\
8.1 \\
12.5\end{array}$ & [11] \\
\hline
\end{tabular}


The high oxygen content in the wear products points to the dominance of oxidizing wear in the Hardox steel samples after nitrogen implantation. Based on Fig. 3, it can be observed that nitrogen and carbon diffuse toward the friction zone. The diffusion of carbon atoms is first recorded here.

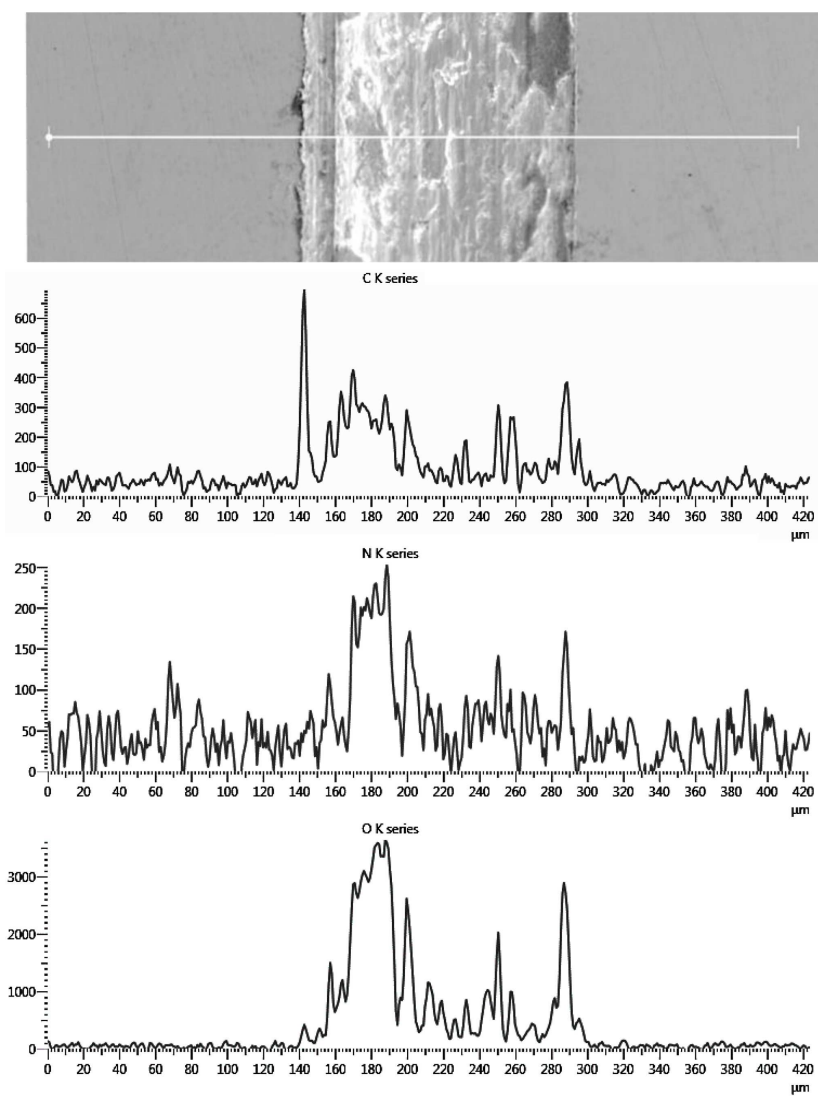

Fig. 3. SEM image of the surface of nitrogen-ion implanted Hardox steel and the scanline of element contents: carbon, nitrogen, oxygen [10].

The lack of difference between the nitrogen content inside the wear trace and that on the sample surface means that the nitrogen content regenerates in the surface layer of the wear trace during the friction process. The shift of the nitrogen atoms to the inside of the sample is caused by accelerated diffusion due to a local temperature increase during friction and the occurrence of radiation defects during implantation. The diffusion of nitrogen was first observed by Jagielski et al. [12] during the tribological tests of commercial steel $(1.4 \mathrm{C}-1.5 \mathrm{Cr}-0.6 \mathrm{Mn}-0.25 \mathrm{Si})$ by the nuclear reaction method.

Since the presence of the long-range effect was confirmed by the tribological test and nanohardness measurements alike, it is now time to explain the causes of this effect. One of these causes is the shift of radiation defects to the inside of the sample, as observed by Sharkeev et al. [4, 13]. These authors claim that the stresses generated by the implanted ions are so high that they lead to the shift of the radiation defects (diffusion) to the inside of the sample, beyond the implanted area where the stresses are lower. In addition, the diffused radiation defects can be shifted to the inside of the material due to the stresses generated either by the indenter during nanohardness testing or by the countersample load in the tribological test. Variations in the stresses generated by the indenter and the countersample can lead to variations in the dislocation range. It can be observed that in tribological testing after the implantation with a fluence of $1 \times 10^{18} \mathrm{~N}^{+} / \mathrm{cm}^{2}$ and a countersample load of $0.49 \mathrm{~N}$, the friction factor decreases at a depth of 3.0(1) $\mu \mathrm{m}-$-Fig. 1. On increasing the load to $0.59 \mathrm{~N}$ and $0.79 \mathrm{~N}$, the long-range effect extends to $3.2(1) \mu \mathrm{m}$ and 3.5(1) $\mu \mathrm{m}$, respectively. The modified layer thickness determined by nanohardness testing is usually higher than that obtained in tribological tests. Nevertheless, microhardness results can contain system errors [5].

As shown by this study, one of the factors leading to the long-range effect is the migration of nitrogen and carbon ions in the friction area during the tribological test.

Since the migration of carbon atoms was confirmed by the tribological results, we can now attempt to determine their range in the sample implanted by ion beam assisted deposition (IBAD), as it was done in the case of nitrogen atoms. Measurements of friction factor for Ti6Al4V alloy implanted with carbon by IBAD using a beam of nitrogen ions with an energy of $120 \mathrm{keV}$ was performed in [14]. The two-step increase in the friction factor, visible in Fig. 6, results from the long-range effect of the implanted nitrogen ions and the recoiling implantation of carbon atoms. The first, very sharp increase is caused by the wear of the carbon-containing layer. The theoretical range of the carbon atoms implanted by IBAD was determined using the SATVAL program [15]. By measuring the wear trace depth of the carbon-containing layer it was possible to determine the depth of the long-range effect and compile Table II for nitrogen atoms in the way it was done in Table I. The other much slower increase in the friction factor is caused by the wear of the layer modified by nitrogen atoms. In terms of accuracy, the measured thickness of the layer modified by nitrogen atoms agrees with the data obtained based on Fig. 1.

The results demonstrate that the thickness of the layer with lower friction and wear factors determined in the tribological test is considerably higher than the initial range

\section{TABLE II}

Parameters describing the surface layer of the Ti6Al4V alloy sample modified by IBAD carbon atoms $\left(k=R_{\mu} / R_{\text {SATVAL }}\right)$.

\begin{tabular}{c|c|c|c|c}
\hline \hline $\begin{array}{c}\text { Energy } \\
\text { of nitrogen } \\
\text { ions }[\mathrm{keV}]\end{array}$ & $\begin{array}{c}\text { Fluence } \\
{\left[\text { ions } / \mathrm{cm}^{2}\right]}\end{array}$ & $\begin{array}{c}R_{\mathrm{SATVAL}} \\
{[\mu \mathrm{m}]}\end{array}$ & $\begin{array}{c}R_{\mu} \\
{[\mu \mathrm{m}]}\end{array}$ & $k$ \\
\hline \multirow{2}{*}{120} & $2 \times 10^{17} \mathrm{~N}^{+}+\mathrm{C}$ & 0.16 & $0.3(1)$ & 1.9 \\
& $5 \times 10^{17} \mathrm{~N}^{+}+\mathrm{C}$ & $1.4(1)$ & 8.8 & 1.9 \\
& $1 \times 10^{18} \mathrm{~N}^{+}+\mathrm{C}$ & $2.1(1)$ & 13.1 &
\end{tabular}


of the implanted ions (atoms). Apart from the migration of radiation defects into the sample, one can observe diffusion of the implanted ions of nitrogen and carbon, the latter being an alloying component of the tested steel. The shift of the nitrogen and carbon atoms occurs due to the accelerated radiation diffusion and diffusion coefficient increase caused by a local temperature increase in the friction node during the tribological test. The modified layer thickness depends on the wear and/or load applied to the sample.

\section{Conclusions}

The results of this study demonstrate that the thickness of the layer with the modified friction and wear factors determined in the tribological test is considerably higher than the initial range of the implanted ions (atoms).

Apart from the migration of radiation defects into the sample, one can observe diffusion of the implanted nitrogen and carbon ions. The shift of nitrogen and carbon atoms occurs due to the accelerated radiation diffusion and increased diffusion coefficient caused by a local temperature increase in the friction node during the tribological test.

It has been found that the modified layer thickness depends on the wear and/or load applied to the sample.

\section{References}

[1] Y.P. Sharkeev, B.P. Gritsenko, S.V. Fortuna, A.J. Perry, Vacuum 52, 247 (1999).

[2] Y.P. Sharkeev, S.A. Gashenko, O.V. Pashchenko, V.P. Krivobokov, Surf. Coat. Technol. 91, 20 (1997).
[3] D.I. Tetelbaum, E.V. Kurilchik, N.D. Latisheva, Nucl. Instr. Meth. Phys. Res. B127, 153 (1997).

[4] Y.P. Sharkeev, E.V. Kozlov, Surf. Coat. Technol. 158, 219 (2002).

[5] A.C. Fischer-Cripps, Vacuum 58, 569 (2000).

[6] P. Budzynski, P. Tarkowski, E. Jartych, A.P Kobzev, Vacuum 63, 737 (2001).

[7] P. Budzynski, Nucl. Instr. Meth. in Phys. Res. B 342, 1 (2015).

[8] P. Budzyński, L. Kara, T. Kücükömeroğlu, M. Kamiński, Vacuum 122, 230 (2015).

[9] J.F. Ziegler, Nucl. Instr. Meth. B 219, 1027 (2004).

[10] P. Budzyński, M. Kamiński, A. Droździel, M. Wiertel, IOP Conf. Ser.: Mater. Sci. Eng. 148, 012045 (2016).

[11] P. Budzyński, M. Kamiński, M. Wiertel, K. Pyszniak, A. Droździel, Acta Phys Pol A 132, 203 (2017).

[12] J. Korycki, A. Dygo, R. Pietrak, A. Turos, G. Gawlik, J. Jagielski, Nucl. Instr. Meth. Phys. Res. B19, 177 (1987).

[13] Y.P. Sharkeev, A.J. Perry, S.V. Fortuna, Surf. Coat. Technol. 108, 419 (1998).

[14] P. Budzynski, J. Sielanko, Acta Phys. Pol. A 128, (2015).

[15] J. Sielanko, J. Smolira M., Annales UMCS Informatica AI 1, 221 (2003). 